\title{
The research on innovation talents training mode reform of mechanical major in construction colleges and universities
}

\author{
Ruiqin $\mathrm{Hao}^{\mathrm{a}}$, Zeguang $\mathrm{Han}^{\mathrm{b}}$ and $\mathrm{Yu} \mathrm{\textrm {Han } ^ { \mathrm { c } }}$ \\ College of Mechanical Engineering, Shenyang Jianzhu University, Shenyang 110168, China \\ ahaoruiqin1@163.com, bhanzeguang1@163.com, '599857215@qq.com
}

Keywords: Innovation, Mechanical Engineering, Talent training.

\begin{abstract}
In order to solve the application ability and innovation ability shortage of the mechanical professional university graduates in Building class colleges and universities, the tentative reform innovation has been done in training Objectives, training scheme, content organization under course system,and assessment methods. The results show the above-mentioned methods are feasible by the implementation of inspection in two terms mechanical professional university graduates in our school.It can be the valuable experience and must be further popularize.
\end{abstract}

\section{Introduction}

The national innovation system is the foundation and engine of economic and social sustainable development,is the cradle of train and bring up high quality talents, and is also the pillar and foundation of national comprehensive competitiveness. The higher education in the national innovation system plays a very important role. The study of the higher education innovation system is the necessity of development of higher education and the state.In order to achieve the goal which the nation's higher education province of liaoning is developing gradually to a powerful province of education, the innovation of higher education system is one of the necessary means. Combined with the old industrial bases are in urgent need of a large number of mechanical innovative talents, therefore their training mode become the very important research subject which is paid great attention and carried on the effective research by all higher education workers. Some fruitful research results have been achieved. The representative achievements are as follows. Firstly, centered on quality education, it focuses on reform the personnel training mode. Such as the students' innovation ability training is completed through four parts,that is to say "cultivate students' problem consciousness", "promoting students of science and technology innovation activities", "education reform the teaching method" and "curriculum system reform" in the mechanical and electrical engineering college by Hohai university. Secondly, The training mode of introducing foreign CDIO teaching idea has been firstly applied in Harbin industrial university and tongji university,whose teaching model of project-based learning realize the equality of teachers and students in the teaching process of mutual cooperation culture by establishing innovation project platform, modifying study plan,etc..Lastly,classification of training model has been adopted by Dalian University of Technology,where the innovative experimental classes ,whose students are separatelly enrollmented every year, have been set up,the independent teaching system and the innovative experiment platform to support students complete innovation idea works design, manufacture and perfect has also been set up.Thus,the a good learning environment to guide the passive learning way of students to be active learning way has been widely established.It is a new training model to rapidly cultivate students to become socially useful talents. Above-mentioned mechanical machinery talents training mode in the respective school culture has made some achievements, but these modeles are based on students overall level is high,and are suitable for 985, 211 key institutions of higher learning. Based on independent college undergraduate mechanical and electrical kind of applied talents training goal, the four aspects reform which are the talent training scheme reform, and innovation talent practice bases construction, talents construction of teachers team and talent education reforms in campus culture construction has been widely used. A large number of qualified applied talents for the society have 
been Cultivated. Guangzhou south China university of technology institute and shenyang city college are an important symbol. For the overall level of independent college students is poor,they are mainly focusing on the skilled personnel training mode,and their talents operational ability is strong.But the students' basic theory base is weak, and their research power is also relative insufficient.Thus,the reform research of mechanical engineering innovative talents training target, training plan ,the decomposition of the targeted content,teaching organization, and evaluation methods in type construction features ordinary institutions of higher learning (between the key universities and "independent college") is our main problem to be solved. It is also imminent to train with the basic theoretical knowledge of appropriate wide interdisciplinary and hands-on ability talents for the social.

\section{Content of the reform idea}

Professional training orientation. The construction of ordinary university personnel training among key universities and independent colleges can't pursue excessivelly the high knowledge level, cannot also relax requirements for the professional technician. They should be combined with its own advantage subject, and cultivates characteristic type talents. Therefore, the construction of institutions of higher learning mechanical professional personnel training target should be positioned in a training for construction machinery in the field of application of the innovative engineering and technology talents.

Training plan and teaching content reform. The current cultivation scheme in most colleges and universities still follows the traditional mode.That is to say, first and second grade students study the basic courses in their university, junior in thecollege studies specialized basic courses,and senior in thecollege studies specialized courses and completes the graduation design too. The teaching contents and demands of the teaching steering committee of the state have been strictly observed. In the actual teaching activities, the teaching contents from one to three year in university have few contact with practical engineering machinery and equipment. Taught knowledge is too abstract, the teaching content has few effective help in later professional course and graduation design. Graduate students in design phase, focus on "blueprints" work hard to have enough time to innovation. The big discussion, such as graduation design (paper) also is it necessary to large range? Whether should have innovation requirements? ,has been triggered recently. At the same time, the wrong feeling among young teachers and graduation students, which is graduation design has nothing to do with the theory of curriculum knowledge, is common.It is shown that The training plan and teaching content reform is imperative.it is not hard to find that college education determines the most graduates career after carefully analyzing the career field of mechanical professional college graduated students on institutions of higher learning.That is to say, what major to learn the knowledge, the future work in the field of counterpart. As the contents of professional courses and graduation design have mainly connected with the mechanical equipment,such as earthmoving and stone equipment, construction crane, bridge engineering machinery, concrete equipment, piling machinery, highway construction equipment,railway line construction machinery and maintenance,etc.,and around these mechanical equipment for targeted teaching. Although there are some common knowledge (abstract theory) between these devices and other mechanical equipment, but more individual knowledge (professional theory) has been embodied. To rapidly develop the talents which graduation can get started, rely on them to enhance the level of engineering machinery equipment, the training plan and teaching content related to construction machinery should be started from the initiation stage. The exact approach is shown in following:(1)Set up four years always tutorial system. New students have been determined the graduation design teachers who complete the decomposition graduation design task according to students' learning stage, assign to each student, regular check, and comprehensive at graduation.(2) Students write and submit report regularly, and form a system. In accordance with the requirements of subject, students write the research report corresponding main course and their stage tasks, guide teacher reviews, and evaluation results are given after each semester.(3)Study gives practice credits, and give teachers teaching points, arouse teachers and students enthusiasm. It must break the existing 
student credit access mode, submit the students really studies included in the results, students obtain corresponding practice credits.It can fully embody the work value, fully arouse the enthusiasm of teachers and students, and is beneficial to the smooth implementation of the training scheme.(4)The college students' innovative undertaking projects are related to the design teams and, teachers, a certain practice credits are given to participating project research students whose innovative entrepreneurial skills can be fully exercised. These measures will be conducive to break the temporary partnership model in the current college students' innovative undertaking project,establish an effective system of project implementation, and put an end to the phenomenon that current college students' innovative entrepreneurial project is just a form of activity, students are not engaged in basic substance in the study, teachers do not have to be really into energy, and a great deal of money be spent for nothing. (5) It is necessary to further increase the intensity of specialized practice teaching,and continuous stable graduate internship practice base construction. It must be break the existing theory teaching mode in the university or colleges of technology, really attach great importance to the specialized practice teaching, allocate the practice stage of graduation design task to each learning stage of four years university study, let students work on the activities in the internship practice base at any time.

To implement the training plan, the corresponding teaching content must be carried out major reforms. Combining the construction of colleges and universities graduate employment direction and specific measures (1), mentor's graduation design task is roughly decomposed into the following contents which are the understanding and the mechanical model of members of the engineering machinery, mechanical conceptual design and innovative entrepreneurial activity, common and special parts structure design and technical pattern expression, motivation and execute component design,and general Structure Design of Equipment,etc..Students will complete on time the periodic report while they are learning the corresponding main cources,such as theoretical mechanics, material mechanics, theory of machines and mechanisms, creative science, machine design, metallic material, fundamentals of machine manufacturing technology, steel structure, structural mechanics, hydraulic transmission, and mechanical control engineering basis,etc.. In teaching process of a liberal education at the same time, the key to two or morethings have been decomposited into the content knowledge guidance. Thus the contents of heavy graduation design will be transferred into each stage of the learning process at four-year period. Students can fully understand how conceived the design of the machine, what specific courses that will solve the problem, their learning enthusiasm and creativity can be vastly stimulated,at the same time the goal of graduation can undertake the design task can be easilly realized. The complex relationship among teacher, graduation design team, device object, content, course and term is shown in Figure 1.

In order to achieve above-mentioned training goal, the traditional talent assessment methods should be appropriate reform. Due to the teaching contents is organized around the engineering machinery equipment and the graduation design topic, therefore,main course examination should be divided into two parts of the theory and engineering application ability whose grade ratio is 8 to 2 . Engineering application ability appraisal result shall be determined by teacher and instructor based on the corresponding study and teacher evaluation.

\section{Conclusions}

Through the above reform, the following benefits can be found.Such as:(1)Students have a clear study objectives from school start, change the present situation of the blank in the future,and feel to look forward.(2) Course learning and graduation design content have loop and pertinence. Students understand clearly the corresponding relationship of their learning content and actual mechanical equipment, can easily overcome the mind obstacle that theory course is too abstract. The unified structure expression among abstract model , components and parts is established, which laid a fou ndation for the creation of the structure design in the future.(3)It can significantly improve the learning efficiency by breaking up the whole into parts. Each school year study content is 
decomposition of graduation design content, all content integration is the graduation design specification or paper. Thus,it can clearly cut down the time of graduation design, the ability to write research report get sufficient exercise.(4)Students can use a lot of their spare time, combine the course content with graduation design,learn and apply with full vigour, fully exercise their creativity.

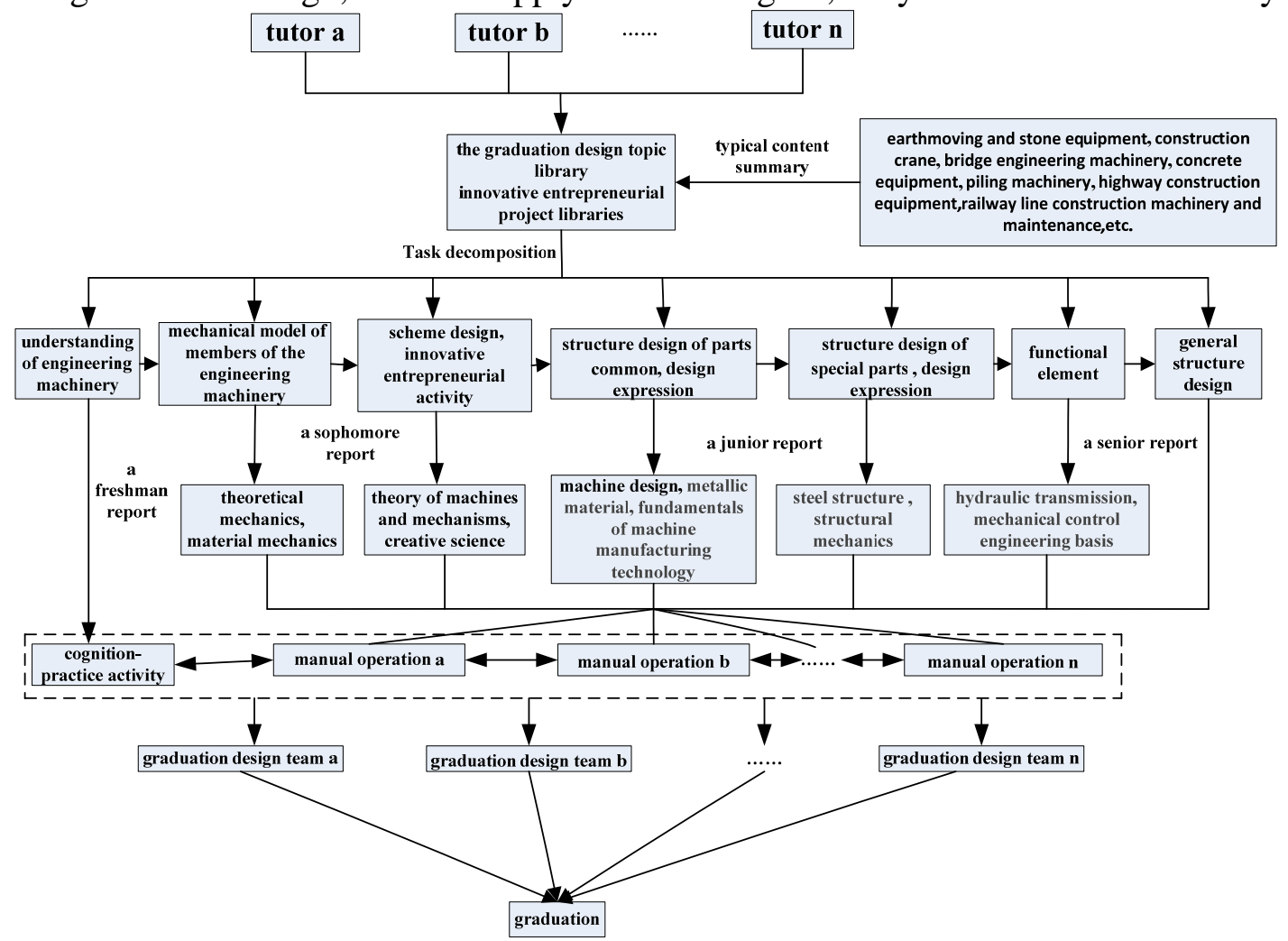

Figure 1 The complex relationship among teacher, graduation design team, device object, content, course and term

The reform plan has received the good effect after tested through practicing in the college students in grade 2011 and 2012. Results reflect the following: Students applying knowledge and solving problem skills have greatly improved. Students take an active part in college students' mechanical innovation design competition and engineering training competition helded by the country or liaoning province. The entries application of knowledge in production working won the national first prize 5 ite$\mathrm{ms}$,the national second prize 6 items; the provincial first prize 10 items, and the provincal second prize 20 items.Our students obtain cheerful achievements in competition, receive the employers the consistent high praise,and are employed in priority by employers. The excellent and good rates of the main courses has been raised from 30\% to 60\%. The first average employment percent is increased from $92 \%$ to $98 \%$, and is in the province's leading position for two consecutive years.

\section{References}

[1] S.Z. Yang, My understanding of CDIO engineering culture education, J. China University Teaching, 9 (2008) 6-7,30

[2] Z.G.Han, R.Q.Hao, The mechanical basic course innovation scheme based on CDIO education concept,Proceedings of 2012 Mechanical Design Conference, hunan,changsha, pp96-99

[3] X.J.Xu, J.Z.Shang, C.Y.Pan, The Investigation and Practice of the Measures of Developing the Innovative Capacity of Mechanical Situation Design of the Cadets in the New Situation, J. of Higher Education Research, 2 (2009) 70-71 